infection in childhood to provide immunity to toxoplasmosis for pregnant women.

1 Fleck DG. Toxoplasmosis. Public Health (London) 1969;83:131-5.

2 Masur H, Jones TC, Lempert JA, Cherubini TD. Outbreak of toxoplasmosis in a family and documentation of acquired retinochoroiditis. Am ₹ Med 1978;64:396-402.

${ }^{3}$ Desmonts G, Couvreur J, Alison F, Baudelot J, Gerbeaux J, Lelong $M$. Étude épidemiologique sur la toxoplasmose: de l'influence de la cuisson des viandes de boucherie sur la fréquence de l'infection humaine. Revue Francaise d'Etudes Cliniques et Biologiques 1965;10:952-8.

${ }^{4}$ Fleck DG, Kwantes W. The laboratory diagnosis of toxoplasmosis. Public Health Laboratory Service Monograph Series No 13. London: HMSO, 1980.

\section{Children born as a result of incest}

After an address to the Medicolegal Society on the crime of incest, Sir Desmond Ackner" asked, "To what extent is it a serious eugenic risk if brother and sister marry ?" There was no response from his audience. Father-daughter and brothersister unions result in inbreeding four times as intense as in first-cousin marriages. The surveys of the extra risks of recessive disorders and congenital malformations to the children of first cousins have not, however, given enough information to permit reliable extrapolation to the children of incestuous unions. There are also obvious difficulties in following up closely children born to a random sample of incestuous unions without causing distress to the families.

Nevertheless, three studies have been reported. The largest, a retrospective survey of 161 children, was from Czechoslovakia $^{2}$ in 1971. Rare recessive or probably recessive disorders found in the children included homocystinuria, adiposogenital syndrome, congenital ichthyosis, retinitis pigmentosa, and deaf-mutism as well as a high incidence of mental retardation. Fewer than half the children were normal. This study might possibly have been biased by some selection in the sources from which the children were ascertained. The other two studies, ${ }^{3}{ }^{4}$ one from England of 13 live-born children followed up for four to six years and one from Michigan of 18 live-born children followed up for six to 12 years, were prospective, with the children being ascertained during their mothers' pregnancies.

Of the 31 children in these two studies-12 born to fatherdaughter and 19 to brother-sister matings-only 13 were normal. Two died from recessive disorders (cystic fibrosis and glycogen-storage disease) and one from an almost certainly recessive disorder causing progressive cerebral degeneration and loss of vision. Two of those alive probably had recessive disorders, both with severe mental retardation with cerebral palsy, and one a possibly recessive disorder, severe non-specific mental retardation. Two others had died in the neonatal period, a baby with very low birth weight and another with respiratorydistress syndrome. Two had congenital malformations, a lethal Fallot's tetralogy and a survivor with bilateral cleft lip. Eight other survivors were mildly mentally retarded with IQs in seven ranging from 59 to 76; the eighth, whose IQ score was not available, was in a school for the educationally subnormal.

This increase in recessive disorders-between three and six cases in 31 children compared with an expected incidence 5 in the general population of two or three per thousand-is in line with expectations. It is compatible with a lesser increase in the children of first cousins, and with the average person carrying one or two recessive genes which when homozygous will cause a serious disorder in live-born children. The average person may well carry further recessive genes which when homozygous will cause early death in utero; but there are no good data on this.

A relatively smaller increase in common congenital malformation, two cases in 31 children compared with about $2 \%$ in the general population, ${ }^{6}$ is also what might be expected. Inbreeding increases the variance of the genetic liability to multifactorial conditions. The increased incidence of mild mental retardation is also noteworthy. It did not, at least in the American series, simply reflect the low level of intelligence of the biological parents. Some lowering of IQ, of less degree, has been found in the offspring of first cousins both from Japan $^{7}$ and from Arabs in Israel. ${ }^{8}$ New prospective studies are needed from northern Europe and North America of the children of both incestuous unions and first-cousin marriages, making use of modern clinical and biochemical screening for recessive disorders-though these would not be easy to arrange. On the present evidence the risks to the children of father-daughter and brother-sister unions, in contrast to those of first-cousin marriages, seem unacceptable. The risks are probably also unacceptably high in the intermediate case of uncle-niece, half sister-half brother, and double first-cousin marriages-except perhaps in communities where a long tradition of close inbreeding has substantially lowered the carrier prevalence of recessive genes.

1 Ackner Sir Desmond. The crime of incest. Med Leg 7 1980;48:79-91.
2 Seemanova E. A study of incestuous mating. Hum Hered $1971 ; 21: 108-28$.
3 Carter CO. Risk to offspring of incest. Lancet $1967 ; 1: 436$.
4 Adams MS, Neel JV. Children of incest. Pediatrics $1967 ; 40: 55-62$.
5 Carter CO. Monogenic disorders. F Med Genet $1977 ; 14: 316-20$.
Leck I. Congenital malformations and childhood neoplasms. F Med Genet
1977;14:321-6.
Schull WJ, Neel JV. The effect of inbreeding on Fapanese children. New
York: Harper and Row, 1965 .
${ }^{8}$ Bashi J. Effect of inbreeding on cognitive performance. Nature 1977; Bashi J. Effect
:440-2.

\section{Colposcopy}

When Hinselmann ${ }^{12}$ first described the colposcope 50 years ago cervical cancer was thought to begin as an invasive lesion in a small focus or nodule. The colposcope was meant to help the human eye identify this first, cancerous spot. For many years descriptions of the instrument and its use were confined to German publications, where a highly specialised and cumbersome colposcopic terminology developed which had little appeal to the English-speaking world. ${ }^{3}$ In time Papanicolau's description ${ }^{4}$ of exfoliative cytology, and a growing awareness of the widespread, subtle, cellular changes within the cervical epithelium that precede invasive cancer, focused the attention of gynaecologists on cervical cytology rather than on colposcopy. This led to more frequent use of cone biopsy-on receipt of a positive cervical smear gynaecologists wanted the pathologist to differentiate between dysplasia, carcinoma-in-situ, and microinvasive or invasive cancer of the cervix. ${ }^{5}$

In North America ${ }^{5}$ and in Britain ${ }^{6}$ the investigation and management of patients with abnormal cervical smears have recently taken a new turn with the reappearance of colposcopy as a technique that bridges the gap between Papanicolau-smear screening and definitive histological diagnosis. Coppleson has 
argued that this resurgence in interest in colposcopy has stemmed from too loose an interpretation of abnormal cervical smears and the too frequent resort to cone biopsy and hysterectomy. Certainly more conservative methods such as cryosurgery or the laser beam have now become accepted as having an important part to play in the management of cervical intraepithelial neoplasia. ${ }^{7} 8$

In large measure this renewed interest in colposcopy in Britain stems from the pioneer work of Anderson in Edinburgh $^{9}$ and Coppleson ${ }^{1011}$ in Oxford, followed by Jordan, ${ }^{12}$ Singer, ${ }^{13}$ and Crompton and Langley. ${ }^{14}$ Coppleson ${ }^{6}$ has claimed that colposcopy has brought a new precision to our understanding of the life history of cervical epithelium in health and disease; in experienced hands it has much to contribute to clinical practice in gynaecology. Kirkup et al ${ }^{15}$ have recently described 451 patients who were referred to their colposcopy clinic because of abnormal cervical cytology or a suspicious appearance of the cervix. Their study confirmed that colposcopically directed biopsy specimens may be used with assurance in reaching an accurate and safe diagnosis in patients with abnormal smears. The upper limit of the lesion was out of sight in the endocervical canal, making a diagnostic cone biopsy necessary in $8.9 \%$ of their cases. This standard of service requires a highly trained colposcopist continuously concerned with the investigation and management of large numbers of patients. The danger is of "underdiagnosis" rather than "overdiagnosis." This is unlikely to happen with skilled colposcopists but those with less experience may advise conservative treatment (local biopsy or cryosurgery) when the lesion warrants further investigation or even wide surgical excision.

Close links need to be made between clinical colposcopy and exfoliative cytology and histopathology. Ideally the colposcopist should be equally skilled in gynaecological pathology and in cytology, but in practice this combination is rare. An experienced, soundly based opinion is required especially when there is a question of conservative treatment. There is no place for inadequately trained colposcopists using the instrument on an occasional basis in small departments or hospitals. The technique with its clear service and important research components, should be based on selected major centres prepared to accept referred cases from surrounding smaller hospitals. We require relatively few colposcopists but they must be very well trained.

1 Hinselmann H. Verbesserung der inspektionsmöglichkeiten von vulva, vagina und portio. Munch Med Wochenschr 1925;72:1733.

2 Hinselmann H. Einführung in die kolposkopie. Hamburg: Hartung, 1933.

3 Stafl A. Colposcopy. Clin Obstet Gynecol 1975;18:195-213.

- Papanicolau GN, Traut HF. Diagnosis of uterine cancer by vaginal smear. New York: Commonwealth Fund, 1943.

bichart RM. The patient with an abnormal pap smear-screening techniques and management. $N$ Englf Med 1980;302:332-4.

- Coppleson M. Colposcopy. In: Stallworthy J, Bourne G, eds. Recent advances in obstetrics and gynaecology. 12th ed. Edinburgh: Churchill Livingstone, 1977:155-87.

7 Townsend DE, Ostergard DR. Cryocauterization for preinvasive cervical neoplasia. F Reprod Med $1971 ; 6: 171-6$.

8 Briggs RM. Dysplasia and early neoplasia of the uterine cervix. A review. Obstet Gynaecol Surv $1979 ; 34: 70-99$.

- Anderson AF. The Van-Watson colposcope. Lancet 1962;ii:813-4.

10 Coppleson $M$. The value of colposcopy in the detection of preclinical carcinoma of the cervix. Three years' experience at King George V Memorial Hospital, Sydney. Fournal of Obstetrics and Gynaecology of the British Empire 1960;67:11-23.

11 Coppleson M. Colposcopy, cervical carcinoma in situ and the gynaecologist. Based on experience with the method in 200 cases of carcinoma in situ. fournal of Obstetrics and Gynaecology of the British Empire 1964;71: 854-70.

12 Jordan JA. Cancer of the cervix uteri with particular reference to cytology. Practitioner 1969;202:351-62.

13 Singer A. The uterine cervix from adolescence to the menopause. $\mathrm{Br} \mathcal{F}$ Obstet Gynaecol 1975 ;82:81-99.
14 Crompton AC, Langley FA. Epithelial abnormalities of the cervix uteri. London: Heinemann, 1973.

15 Kirkup W, Singer A, Hill AS. The accuracy of colposcopically directed biopsy in patients with suspected intraepithelial neoplasia of the cervix. Br $\mathcal{F}$ Obstet Gynaecol 1980;87:1-4.

\section{"New" cardiopulmonary resuscitation}

Cardiopulmonary resuscitation is one of the few lifesaving procedures in medicine; so when fundamental changes are proposed in the way in which such procedures are conducted it becomes an important issue for any doctor. The superiority of expired air resuscitation over manual methods (Holger Nielson, Silvester Brosch) has been proved by comparison of arterial oxygen levels in medical student volunteers subjected to the various methods. ${ }^{1}$ Nevertheless, while clinical evidence has firmly established the place of expired air resuscitation for the support of ventilation, no such evidence exists to resolve arguments over the correct way to support circulation.

Two decades ago Kouwenhoven and his colleagues at Johns Hopkins Hospital showed that a peripheral pulse could be generated from an arrested heart by manual compression of the chest wall. ${ }^{2}$ The quality of cardiac massage was frequently assessed with a finger on the femoral pulse, but-as MacKenzie et al pointed out-this pulsation resulted from a systolic pressure wave and did not necessarily mean that there was forward flow of blood. ${ }^{3}$ The pulse wave was attributed to emptying of the heart by squeezing it in a sandwich formed by sternum and spine. Recent work by Rudikoff $e t a l^{4}$ and Chandra et $a^{5}$ has clearly shown that this explanation is just not true.

The recent "Wolf Creek II" meeting on cardiopulmonary resuscitation discussed the scientific basis for providing modifications in cardiopulmonary resuscitation, every bit as revolutionary as Kouwenhoven's first observations. Two fundamental questions needed to be answered. Firstly, if the heart is considered to be a passive chamber, how does external compression cause forward blood flow rather than flow in both directions along the arteries and back up the thoracic veins? Secondly, how is optimal blood flow to be obtained? Werner and his colleagues had used two-dimensional echocardiography to show that during chest compression (systole) the atrioventricular valves remain open. Regurgitation of blood is prevented by venous valves at the superior thoracic inletbeautifully demonstrated by Criley with cineangiography. During relaxation (diastole) only the aortic valve remains competent, preventing blood from flowing back into the left ventricle.

Argument remains whether the chest and all the hollow vessels within it constitute the primary pump, or whether this is the heart alone. Nevertheless, Weisfeldt supported the idea of the chest as a pump by showing that forward blood flow is augmented when intrathoracic pressure is increased by inflating the lungs concordantly with compression of the chest instead of discordantly, as is currently recommended. Most of the cardiopulmonary experts agreed with the implications of earlier work suggesting that chest compressions should be delivered more slowly than $60 / \mathrm{min}$, ensuring that at least half of the cycle is spent in systole. ${ }^{6}$

"New" cardiopulmonary resuscitation may well prove an important therapeutic advance but it is largely untried in man. 